\title{
Disabilities in survivors of low birthweight
}

\author{
E ALBERMAN, J BENSON, AND W KANI
}

Department of Clinical Epidemiology, London Hospital Medical College and Department of Child Health, King's College School of Medicine and Dentistry

SUMmARY A study of those survivors weighing $2000 \mathrm{~g}$ or less at birth born to residents of the South East Thames Regional Health Authority in 1970, '71, and '73 was carried out by abstracting data from health visitors' and school health records. Some postnatal information was available for $78 \%$ of the children. Prevalences of reported impairments in relation to birthweight were $20 \%$ in babies of $1500 \mathrm{~g}$ or less, $13 \%$ in the group weighing 1501 to $1750 \mathrm{~g}$, and $11 \%$ for those of 1751 to $2000 \mathrm{~g}$. Only half the impairments in the first group were likely to be seriously disabling, and only a fifth were of obvious prenatal origin. In the heaviest group, about $3 \%$ were likely to become severely disabled, but in over two fifths with impairment, this was likely to be of prenatal origin and therefore more difficult to prevent. This factor together with the larger number of survivors of birthweight 1751 to $2000 \mathrm{~g}$ than of $1500 \mathrm{~g}$ or less, indicate that an increase in impairments may be seen in the heavier group if their mortality continues to fall.

The increase in risk of early mortality and morbidity with falling birthweight has been intensively studied, particularly the relation between mortality and morbidity and the changes that have been observed over time. ${ }^{1-3}$ In recent years, attention has been focussed largely on the lowest birthweight groups, those under $1000 \mathrm{~g}^{4}$ and between 1000 and $1499 \mathrm{~g} .{ }^{5}$ Less has been written about the next weight group, 1500 to $1999 \mathrm{~g}$, although it is known that the risks of mortality and morbidity remain high in relation to babies of average weight. Moreover, although babies of the higher weight group are only slightly more common than those of $1500 \mathrm{~g}$, or less (in England in 1983 their incidence was $1.3 \%$ of livebirths compared with $0.9 \%$ who weighed $1500 \mathrm{~g}$ or less), their neonatal mortality is only one sixth of that of babies of lower weight. Consequently, at the age of one month, the number of survivors in this group is 10 times as large. ${ }^{6}$

A follow up study of babies weighing $2000 \mathrm{~g}$ or less born in South East Thames Regional Health Authority (SETRHA) in the early 1970s, ${ }^{37}$ and derived from some 145000 to 146000 births, enabled us to look separately at impairments reported in babies weighing $1500 \mathrm{~g}$ or less and those weighing 1501 to $2000 \mathrm{~g}$. These findings are described in the following account, which also distinguishes, as far as was possible, between impairments of prenatal and later origin.

\section{Methods}

Birth sample. The sample was derived from children born in 1970, 1971, and 1973 to mothers resident within the 1974 boundaries of the SETRHA. This sample has been described in earlier reports. ${ }^{37}$ Birth notifications and maternity registers in the region for the relevant years were scanned in 1974, and all live and stillbirths of $2000 \mathrm{~g}(4 \mathrm{lb} \mathrm{6oz})$ or less at birth were selected for study. These amounted to 3825 live and stillbirths. Available birth data included place of birth, birthweight, whether live or stillborn, multiple or single birth, and any recorded malformation. A comparison with the routinely collected statistical returns of low birthweight births to the Department of Health ${ }^{6}$ showed that the original sample comprised virtually the same number of births of this weight as had been notified.

Follow-up. The outcome of the livebirths in the sample was followed up in several different ways. Firstly, when the surviving children would have been between 3 to 6 years old, a search for their records was made on our behalf at the Southport NHS Register, and the Office of Population Censuses and Surveys (OPCS) generously provided us with information on whether the child had died, and if so the date and the registered cause of death. Where the children had survived we were given the 
name of the Family Practitioner Committee with which they were currently registered, unless they were adopted, had emigrated, their father was in the Armed Forces, or in a small number of cases, were untraceable. The Family Practitioner Committees gave us the Area Health Authority of residence of the children, and the relevant community medicine specialists and nursing officers helped us with the further follow up.

The main aim was to obtain medical information for those children who were traceable. For the 1970 and 1971 births still resident in SETRHA, the health visitors caring for the children were requested to complete a simple form to give some indication of the children's health status before school entry, but it proved impossible to repeat this exercise for the 1973 cohort. Wherever possible, however, information from the school medical records for all three birth cohorts was obtained, by members of the survey team where the children were still resident in SETRHA, and by the Area Specialists in Community Medicine (Child Health) for those who had moved outside. Because the team was unable to scrutinise the records of the children who had moved, these are described separately in Tables 5 and 6 below. No attempt was made to see any of the children. Practice regarding the obtaining of parental permission to see the school records varied, some areas regarding this as a legitimate exercise not requiring such permission, others seeking permission before allowing access. In the latter areas the proportion of children for whom we obtained follow up data was somewhat reduced, for while parental refusal was very rare, non-response was relatively common.

As is implied by this complicated method of data collection, there was no standard format of health data for the children traced. To validate the data abstracted from the available records, however, and to check for missing data, district handicap registers in SETRHA were searched, and efforts were made to ascertain from multiple sources all known cases of cerebral palsy born in these years and still resident in the region (Evans, Elliott, Alberman, and Evans; in preparation).

Table 1 summarises the success with which the children were followed up. These data can be used as denominators to estimate birthweight specific prevalence rates of different defects. For cerebral palsy in regional residents the total number of survivors resident in SETRHA with or without follow up data can be used with some confidence as a denominator. For other impairments, not always fully recorded on handicap registers, appropriate denominators might be only those for whom medical information is available. This will be discussed in more detail below.

A log linear model analysis was carried out to test whether the success rate of tracing the surviving children varied between groups of different birthweights or between different gestational ages. This showed no significant differences for children for whom the birthweight and gestational age were known, but for the $1.4 \%$ children for whom the exact birthweight was not known (although they were reported as being under $2000 \mathrm{~g}$ ), or for the

Table 1 Survival and numbers traced, with and without postnatal medical information, by birthweight

\begin{tabular}{|c|c|c|c|c|c|c|c|c|c|c|}
\hline \multirow{3}{*}{$\begin{array}{l}\text { Survival and tracing } \\
\text { at school age }\end{array}$} & \multicolumn{10}{|c|}{ Birthweight $(g)$} \\
\hline & \multicolumn{2}{|c|}{$<1500$} & \multicolumn{2}{|c|}{$1501-1750$} & \multicolumn{2}{|c|}{$1751-2000$} & \multicolumn{2}{|c|}{$\begin{array}{l}\text { Exact weight } \\
\text { not known } \\
\text { but under } \\
2000\end{array}$} & \multicolumn{2}{|l|}{ All } \\
\hline & No & $(\%)$ & No & $(\%)$ & No & $(\%)$ & No & $(\%)$ & No & $(\%)$ \\
\hline Stillbirth & \multicolumn{2}{|l|}{495} & \multicolumn{2}{|l|}{134} & \multicolumn{2}{|l|}{164} & \multicolumn{2}{|l|}{79} & \multicolumn{2}{|l|}{872} \\
\hline Neonatal death & \multicolumn{2}{|l|}{573} & \multicolumn{2}{|l|}{142} & \multicolumn{2}{|l|}{119} & \multicolumn{2}{|l|}{47} & \multicolumn{2}{|l|}{881} \\
\hline Death after first month & \multicolumn{2}{|l|}{14} & \multicolumn{2}{|l|}{16} & \multicolumn{2}{|l|}{31} & \multicolumn{2}{|l|}{2} & \multicolumn{2}{|l|}{63} \\
\hline Survivors & 442 & $(100)$ & 502 & $(100)$ & 1033 & $(100)$ & 32 & $(100)$ & $20(29$ & $(100)$ \\
\hline Untraced & 39 & $(8 \cdot 8)$ & 44 & $(8 \cdot 8)$ & 90 & $(8.7)$ & 2 & $(6 \cdot 3)$ & 175 & $(8 \cdot 7)$ \\
\hline \multicolumn{11}{|l|}{ Out of SETRHA } \\
\hline+ no postnatal information & 18 & $(4 \cdot 1)$ & 21 & $(4 \cdot 2)$ & 50 & $(4 \cdot 8)$ & 9 & $(28 \cdot 1)$ & 98 & $(4 \cdot 9)$ \\
\hline \multicolumn{11}{|l|}{ In SETRHA } \\
\hline+ no postnatal information & 34 & $(7 \cdot 7)$ & 35 & $(7 \cdot 0)$ & 99 & $(9 \cdot 6)$ & 2 & $(6 \cdot 3)$ & 170 & $(8 \cdot 5)$ \\
\hline \multicolumn{11}{|l|}{ Out of SETRHA } \\
\hline+ postnatal information & 65 & $(14 \cdot 7)$ & 58 & $(11 \cdot 5)$ & 100 & $(9 \cdot 7)$ & 3 & $(9 \cdot 4)$ & 226 & $(11 \cdot 2)$ \\
\hline \multicolumn{11}{|l|}{ In SETRHA } \\
\hline+ postnatal information & 286 & $(64 \cdot 7)$ & 344 & $(68 \cdot 5)$ & 694 & $(67 \cdot 2)$ & 16 & $(50 \cdot 0)$ & 1340 & $(66 \cdot 7)$ \\
\hline \multicolumn{11}{|l|}{ Postnatal information } \\
\hline available & 351 & $(79 \cdot 4)$ & 402 & $(80 \cdot 0)$ & 794 & $(76 \cdot 9)$ & 19 & $(59 \cdot 4)$ & 1566 & $(77 \cdot 9)$ \\
\hline
\end{tabular}

SETRHA = South East Thames Regional Health Authority. 
$8.9 \%$ children whose gestational age was not known, the tracing rate was significantly lower.

Ascertainment and classification of impairment. As indicated above, data on impairments were collected from birth, health visitor, and school records and from handicap registers. For the purpose of the present account, only impairments in children surviving to school age have been considered. These were classified as 'prenatal' where there was a genetic or chromosomal defect, or where there were malformations or stigmata likely to be of prenatal origin. Neurological, intellectual, or sensory impairments without any evidence of a prenatal origin were considered separately. It often seemed probable that perinatal and postnatal circumstances had contributed to the aetiology of these impairments, or that some were in fact prenatal but without supporting evidence. As well as being included in these groups where appropriate, the cases of cerebral palsy will be described separately.

Impairments of a clearly postneonatal origin, such as those due to accidents or later infection are not included. Also excluded are impairments such as hernias or undescended testicles and hypospadias which we felt were not completely recorded.

\section{Results}

Prenatal group. A brief description of the impairments which were probably of prenatal origin, grouped by birthweight, is given in Table 2 . It will be seen that a proportion of these impairments are likely to prove severely handicapping throughout life; others, if treated early, should be without important sequelae. Data in Table 3 relate the numbers of these impairments to the denominator populations from which they were derived.

When the large group of babies weighing between 1501 and $2000 \mathrm{~g}$ was subdivided further into those above and below $1750 \mathrm{~g}$ it became clear that it was in the heavier (and often more gestationally mature) babies that the prevalence of impairments of probable prenatal origin was the highest (Table 3). Among all 1033 of these survivors, with or without postnatal information, there were three children with Down syndrome, about twice the number expected in a random sample. There were also eight cases of congenital heart disease, also about twice the number expected considering that these exclude stillbirths and later deaths, and include about 200 children for whom we had no postnatal information. A reported four children said to have congenital dislocation of the hips, and five with talipes is also about twice the number one might expect, and may be related to the high incidence of breech presenta- tion in low birthweight babies. The prevalence of impairments of probable prenatal origin in the babies of lower birthweight was somewhat less, although it is notable that there were at least two children with spina bifida among the 442 school age survivors of $1500 \mathrm{~g}$ or less.

Impairments or disabilities without evidence of prenatal origin. The remaining 'impairments' were largely of the type described as neurodevelopmental disability by Drillien. ${ }^{8}$ The disabilities of the affected children, who comprised those with neurological, intellectual, behavioural, and sensory disabilities, could not have been diagnosed at birth, and the most reliable ascertainment was in those children still resident in the health region for whom we had postnatal information. Table 4 gives the data in these children by birthweight group, and ordered in mutually exclusive groups. The order is in the ranking as given, so that any child counted in the first group of severe educational subnormality would not again appear below, even if any of the other disabilities listed were also present. Any child already included in the prenatal group (Table 2) was excluded from Table 4.

The overall prevalence of children with one or more of these disabilities fell from $16.1 \%$ in those weighing $1500 \mathrm{~g}$ or less at birth, to $10 \cdot 5 \%$ and $7 \cdot 1 \%$ respectively in those weighing 1501 to $1750 \mathrm{~g}$ and 1751 to $2000 \mathrm{~g}$. Even without the children with cerebral palsy there was a gradient of risk with birthweight, the percentage of affected children falling from $10 \cdot 2 \%$ to $7 \cdot 0 \%$ to $5 \cdot 1 \%$ in the respective birthweight groups.

Not all these children were severely disabled. Since the children were not seen or assessed in a standard fashion, only an approximate estimate of severity can be given. If one assumes that those who were severely educationally subnormal or had cerebral palsy, or both, and those remaining children who were blind or partially sighted or deaf or partially deaf are likely to be seriously disabled, the prevalence fell from $10 \%$ in the lowest weight group to $4 \%$ and $3 \%$ in each of the next two weight groups.

Nevertheless, because of the relative sizes of the groups, the actual numbers of affected children, were greatest in the two highest birthweight groups (Table 4). Taking only those thought to be severely disabled as described above, 29 came from the group of $1500 \mathrm{~g}$ or less, and 15 and 22 respectively from the next two birthweight groups, so that a small majority of cases are among the heavier babies.

If all impairments in the prenatal and other group were added together, regardless of severity, and only taking SETRHA residents with postnatal 
information, these would amount to $20 \%, 13 \%$, and $11 \%$ respectively of the birthweight groups in ascending order, but the number of children affected would be 60,45 , and 84 respectively (data from Table 3 and Table 4).
All cerebral palsy. Sixty children among all survivors at school age were classified as having a form of cerebral palsy, whether of obvious prenatal origin or not. These included one case in a child with Down syndrome. Table 5 summarises the data on these

Table 2 Prenatally caused or predisposed impairment as described in the medical records in relation to birthweight

\begin{tabular}{|c|c|c|c|c|}
\hline Condition & Birthweight $(g)$ & $\begin{array}{l}\text { Resident } \\
\text { in/out of } \\
\text { SETRHA }\end{array}$ & $\begin{array}{l}\text { Postnatal } \\
\text { information }\end{array}$ & Gestation \\
\hline Bonnevie-Ulrich syndrome & 1174 & In & Yes & 32 \\
\hline Hallerman-Streiff syndrome & 1348 & In & Yes & 37 \\
\hline Malabsorptive syndrome (?what) & 1420 & In & Yes & 28 \\
\hline ?Metabolic disease & 1200 & In & Yes & - \\
\hline Spina bifida & 1843 & Out & Yes & 33 \\
\hline Ileal atresia & 1020 & In & Yes & - \\
\hline \multicolumn{5}{|l|}{ Duodenal atresia and bilateral } \\
\hline congenital dislocated hips & 1275 & In & Yes & 36 \\
\hline Left congenital dislocated hip & 1247 & In & No & 30 \\
\hline Talipes & 1200 & In & Yes & 31 \\
\hline VSD and spastic diplegia & 1072 & Out & Yes & 29 \\
\hline Congenital malformation (? what) & 1270 & In & No & - \\
\hline Congenital malformation (? what) & 1361 & Out & Yes & - \\
\hline \multicolumn{5}{|l|}{ Dextrotransposition of the great } \\
\hline vessels and cerebral palsy & 1612 & In & Yes & 32 \\
\hline VSD & 1668 & In & Yes & 30 \\
\hline VSD & 1724 & In & Yes & 38 \\
\hline $\mathrm{CDH}$ & 1671 & In & Yes & - \\
\hline $\mathrm{CDH}$ & 1744 & In & Yes & - \\
\hline Imperforate anus & 1724 & In & Yes & 36 \\
\hline Extra ureter & 1700 & In & Yes & 31 \\
\hline Congenital malformation of limbs & 1700 & Out & Yes & 33 \\
\hline ?Congenital malformation (? what) & 1644 & In & Yes & - \\
\hline Down syndrome & 2000 & In & Yes & - \\
\hline Down syndrome & 2000 & In & Yes & 28 \\
\hline Down syndrome & 1850 & Out & Yes & 39 \\
\hline Chromosomal defect (?what) & 1920 & In & Yes & 40 \\
\hline Franceschetti-Klein syndrome & 1780 & In & Yes & 39 \\
\hline Spherocytosis & 1780 & In & Yes & 36 \\
\hline Dwarfism & 1973 & In & Yes & - \\
\hline Hirschsprung's disease & 1956 & In & No & 39 \\
\hline Congenital heart disease & 1927 & Out & Yes & 31 \\
\hline Congenital heart disease & 1740 & In & Yes & 30 \\
\hline VSD & 1928 & In & Yes & 40 \\
\hline VSD & 1899 & In & Yes & - \\
\hline VSD & 1928 & In & Yes & 35 \\
\hline Aortic stenosis & 1918 & In & Yes & 40 \\
\hline Aortic stenosis & 1863 & In & Yes & 36 \\
\hline Defective valve & 1836 & In & Yes & 38 \\
\hline CDH & $\begin{array}{l}1030 \\
1928\end{array}$ & In & Yes & 32 \\
\hline CDH & 1960 & In & Yes & 32 \\
\hline $\mathrm{CDH}$ & 1766 & In & Yes & 32 \\
\hline $\mathrm{CDH}$ & 1850 & Out & Yes & - \\
\hline Talipes & 1808 & In & Yes & 32 \\
\hline Talipes & 1899 & In & Yes & - \\
\hline Talipes & 1761 & In & Yes & - \\
\hline Talipes & 1842 & Out & Yes & - \\
\hline Talipes with cerebral palsy & 1985 & In & Yes & 35 \\
\hline Exomphalos & 1920 & In & Yes & 37 \\
\hline Webbed toes & 1850 & In & Yes & - \\
\hline Syndactyly & 1871 & In & Yes & 40 \\
\hline Port wine stain & 1758 & In & Yes & - \\
\hline Port wine stain & 1939 & In & Yes & - \\
\hline Congenital malformation (?what) & 1984 & Out & Yes & - \\
\hline ?Worster-Drought syndrome & 2000 & In & Yes & 38 \\
\hline Rubella embryopathy & 1925 & In & Yes & 38 \\
\hline
\end{tabular}


Table 3 Percentage of survivors with impairments of prenatal origin by birthweight-calculated out of different denominator populations (no in parenthesis)

\begin{tabular}{|c|c|c|c|c|}
\hline \multirow[t]{2}{*}{ Population } & \multicolumn{4}{|c|}{ Birthweight (g) } \\
\hline & $<1500$ & $1501-1750$ & $1751-2000$ & $\begin{array}{l}\text { All (including } \\
\text { birthweight } \\
\text { uncertain) }\end{array}$ \\
\hline $\begin{array}{l}\text { Resident in SETRHA } \\
\text { with postnatal information }\end{array}$ & $\begin{array}{l}3 \cdot 1 \\
(9 / 286)\end{array}$ & $\begin{array}{l}2 \cdot 4 \\
(8 / 334)\end{array}$ & $\begin{array}{l}4 \cdot 2 \\
(29 / 694)\end{array}$ & $\begin{array}{l}3 \cdot 4 \\
(46 / 134())\end{array}$ \\
\hline $\begin{array}{l}\text { Presumed resident in SETRHA } \\
\text { with or without postnatal information }\end{array}$ & $\begin{array}{l}3 \cdot 4 \\
(11 / 32(0)\end{array}$ & $\begin{array}{l}2 \cdot 2 \\
(8 / 369)\end{array}$ & $\begin{array}{l}3 \cdot 8 \\
(30 / 793)\end{array}$ & $\begin{array}{l}3 \cdot 2 \\
(49 / 1510)\end{array}$ \\
\hline All survivors & $\begin{array}{l}3 \cdot 2 \\
(14 / 442)\end{array}$ & $\begin{array}{l}1 \cdot 8 \\
(9 / 5(1) 2)\end{array}$ & $\begin{array}{l}3 \cdot 4 \\
(35 / 1033)\end{array}$ & $\begin{array}{l}2 \cdot 9 \\
(58 / 20(9))\end{array}$ \\
\hline
\end{tabular}

Table 4 Impairments without prenatal origin by birthweight group mutually exclusive groups (survivors with postnatal information; residents in SETRHA only)

Birthweight (g)

$<1500 \quad 1501-1750 \quad 1751-2000$

Impairment group ranked

Educationally subnormal (severe)

Cerebral palsy other than prenatal

Blind/partially sighted

Deaf/partial hearing

Educationally subnormal (mild) and/or

speech or language impairment

Epileptic

Behaviour abnormality

Other

Total

$\%$ (no) of survivors

$\%$ (no) of survivors after excluding

the cerebral palsy group

$\begin{array}{lcc}4 & 3 & 7 \\ 15 & 10 & 9 \\ 3 & 1 & - \\ 7 & 1 & 6 \\ 13 & 18 & 15 \\ 1 & 1 & 7 \\ 0 & 1 & 4 \\ 3^{*} & 1 & 1 \\ 46 & 36 & 49 \\ 16 \cdot 1 & 10 \cdot 5 & 7 \cdot 1 \\ (46 / 286) & (36 / 344) & (49 / 694) \\ 10 \cdot 2 & 7 \cdot 0 & 5 \cdot 1 \\ (27 / 266) & (23 / 329) & (35 / 680)\end{array}$

*Includes two cases of the Wilson-Mikity syndrome, one definite, one probable.

Table 5 Percentage of survivors with cerebral palsy $(C P)$ by birthweight and place of residence

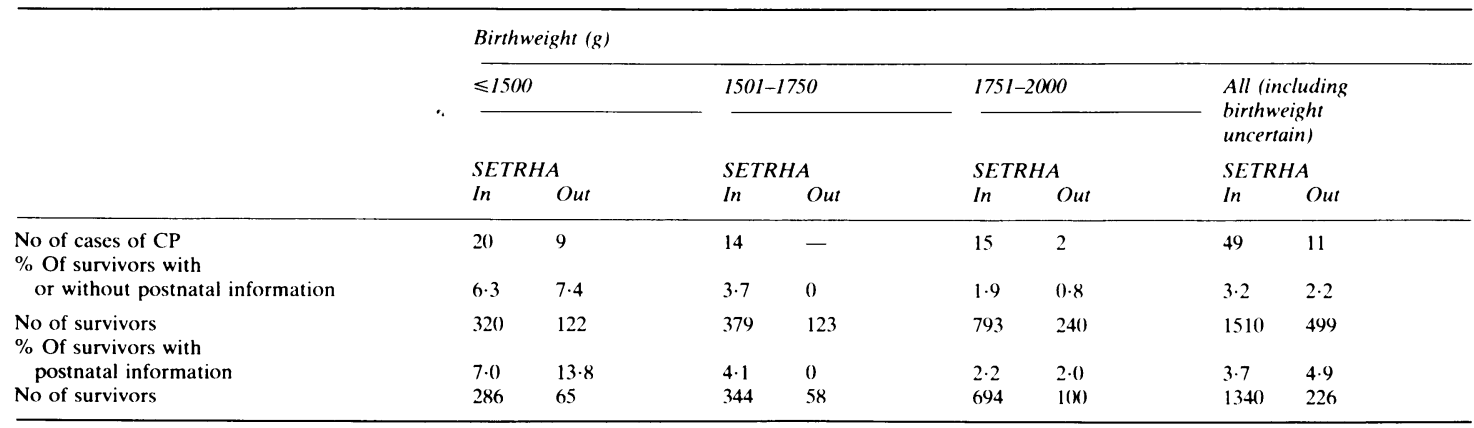

children and shows the expected steep downward gradient in prevalence with rising birthweight. Table 5 also shows the biases that may be introduced by including or excluding missing data. Thus, it seemed that we more often obtained reports on affected than non-affected children if they were in the lowest birthweight group and resident outside SETRHA. For instance, the calculated percentage of children with cerebral palsy who had moved outside SETRHA varied from $7 \cdot 4 \%$ if the denominator used was 
Table 6 Percentage with cerebral palsy by birthweight in relation to likely degree of handicap and residence in or out of SETRHA

\begin{tabular}{|c|c|c|c|c|c|c|c|c|}
\hline & \multicolumn{8}{|c|}{$\begin{array}{l}\text { Birthweight (g) } \\
\text { Residence (in/out SETRHA) }\end{array}$} \\
\hline & \multicolumn{2}{|c|}{$\leqslant 1500$} & \multicolumn{2}{|c|}{$1501-1750$} & \multicolumn{2}{|c|}{$1751-2000$} & \multicolumn{2}{|c|}{$\begin{array}{l}\text { All (including } \\
\text { birthweight } \\
\text { uncertain) }\end{array}$} \\
\hline & \multicolumn{2}{|c|}{ SETRHA } & \multicolumn{2}{|c|}{ SETRHA } & \multicolumn{2}{|c|}{ SETRHA } & \multicolumn{2}{|c|}{ SETRHA } \\
\hline \multicolumn{9}{|l|}{ Likely degree of handicap } \\
\hline Severe & 5 & 4 & 3 & - & 6 & - & 14 & 4 \\
\hline Moderate & 6 & 4 & 4 & - & 2 & - & 12 & 4 \\
\hline Mild & 9 & 1 & 7 & - & 7 & 2 & 23 & 3 \\
\hline Total & 20 & 9 & 14 & 0 & 15 & 2 & 49 & 11 \\
\hline \multicolumn{9}{|l|}{ No of survivors with or } \\
\hline Severe $(\%)$ & 1.6 & $3 \cdot 3$ & $0 \cdot 8$ & - & 0.8 & - & 0.9 & 0.8 \\
\hline Moderate (\%) & 1.9 & $3 \cdot 3$ & $1 \cdot 0$ & - & $0 \cdot 2$ & - & $0 \cdot 8$ & $0 \cdot 8$ \\
\hline Mild (\%) & $2 \cdot 8$ & $0 \cdot 8$ & 1.8 & - & $0 \cdot 9$ & $0 \cdot 8$ & $1 \cdot 5$ & 0.6 \\
\hline \multicolumn{9}{|l|}{ No of survivors with } \\
\hline postnatal information & 286 & 65 & 344 & 58 & 694 & 100 & 1340 & 226 \\
\hline Severe $(\%)$ & 1.7 & $6 \cdot 1$ & 0.9 & - & $0 \cdot 9$ & - & $1 \cdot 0$ & 1.9 \\
\hline Moderate (\%) & $2 \cdot 1$ & $6 \cdot 1$ & $1 \cdot 2$ & - & $0 \cdot 3$ & - & 0.9 & 1.8 \\
\hline Mild (\%) & $3 \cdot 1$ & 1.5 & $2 \cdot 0$ & - & $1 \cdot 0$ & $2 \cdot 0$ & $1 \cdot 7$ & 1.4 \\
\hline
\end{tabular}

all such survivors, to $13 \cdot 8 \%$ if the denominator was only those with medical information, although this difference is not statistically significant.

Again, in spite of the sharp fall in the birthweight specific prevalence rate, the increasing number of children in the heavier weight groups meant that just over one half of the children with cerebral palsy in this study had weighed more than $1500 \mathrm{~g}$.

From the clinical information available the cases were classified as likely to be severely, moderately, and mildly handicapped. The severely handicapped class included those with severe educational subnormality or blindness, or both; the moderate class included the remainder who had severe locomotor and other problems or were either in wheelchairs or walking only with aids. All others were classed as likely to be mildly handicapped. Table 6 shows that the three groups were fairly evenly distributed.

\section{Discussion}

The findings in this survey of outcome of low birthweight in births occurring in the early 1970s are closely comparable with previously published data, most relating to births of under $1500 \mathrm{~g}$ (or $1500 \mathrm{~g}$ or less). The prevalence of reported impairments in the latter group between birth and the ages of 5 to 8 years is of the order of $20 \%$, but perhaps only half are seriously disabled. The best estimate of the prevalence of cerebral palsy in this group is $6 \cdot 3 \%$, a figure identical to that given by McDonald, ${ }^{9}$ obtained by averaging the findings of several surveys of births occurring at the same period.

The main aim of the present report is to draw attention to the need to monitor outcome of babies weighing 1501 to $2000 \mathrm{~g}$ as well as those of a lighter weight. The percentage with reported impairments varied from 13 to $11 \%$ in the subgroups weighing 1501 to 1750 , and 1751 to $2000 \mathrm{~g}$, but in the latter group twice as many than in the groups below $1751 \mathrm{~g}$ birthweight were probably of prenatal origin. The present study suggests that it may be particularly in this group of weighing 1750 to $2000 \mathrm{~g}$, with a lower mortality rate and a relatively higher prevalence of impairments of prenatal origin, that further falls in early mortality which we may confidently anticipate, may result in a further increase in the number of children surviving with such impairments. Current progress in neonatal care, however, gives cause to hope that this increase is likely to be balanced by a decrease in impairments of perinatal origin.

We thank the numerous paediatricians, community physicians, clinical medical officers, school nurses, and local authority clerical officers in SETRHA for their collaboration, Miss M Elliott, Mrs M Egan, and Miss A Dale for help with the collection and preparation of data, and L Jankowski, D Harrison, and S Evans for assistance with data processing and analysis. The study was supported by a grant from DHSS, and OPCS gave generous help.

\section{References \\ 1 Paneth N, Kiely JL, Stein Z, Susser M. Cerebral palsy and new-born care. III. Estimated prevalence rates of cerebral palsy under differing rates of mortality and impairment of low birthweight infants. Dev Med Child Neurol 1981;23:801-7.}


${ }^{2}$ Hagberg B, Hagberg G, Olow I. Gains and hazards of intensive neonatal care: an analysis from Swedish cerebral palsy epidemiology. Dev Med Child Neurol 1982;24:13-9.

3 Alberman E, Benson J, McDonald A. Cerebral palsy and severe educational subnormality in low birthweight children: a comparison of births in 1951-53 and 1970-73. Lancet 1982;i:606-8.

${ }^{4}$ Kitchen W, Orgill A, Lissenden J, Yu V, Drew J. Outcome in infants with birth weight 500 to $999 \mathrm{gm}$ : a regional study of 1979 and 1980 births. $J$ Pediatr 1984;104:921-7.

5 Saigal S, Rosenbaum P, Stoskopf B, Milner R. Follow-up of infants 501 to $1500 \mathrm{gm}$ birth weight delivered to residents of a geographically defined region with perinatal intensive care facilities. J Pediatr 1982;100:606.

6 Department of Health and Social Security. Statistics and Research Division, Birth Notifications for 1970, 1971, 1973, and 1983.
7 Alberman E, Benson J, Evans S. Visual defects in children of low birthweight. Arch Dis Child 1982;57:818-22.

${ }^{8}$ Drillien C, Drummond M. Developmental screening and the child with special needs: a population study of 5000 children. Clinics in developmental medicine no 86. London: SIMP/ Heinemann Medical, 1983.

${ }^{9}$ McDonald A. Is the outcome of very low birthweight improving? In: Adinolifi M, Benson P, Giannelli F, Seller M, eds. Paediatric research: a genetic approach. London: SIMP/ Heinemann Medical, 1982.

Correspondence to $\mathrm{Dr} \mathrm{E}$ Alberman, Department of Clinical Epidemiology, The London Hospital Medical College, London E1 1BB.

Received 16 April 1985 